\title{
Inhibitory effects of bee venom on Propionibacterium acnes- induced inflammatory skin disease in an animal model
}

\author{
HYUN-JIN AN ${ }^{1 *}$, WOO-RAM LEE ${ }^{1 *}$, KYUNG-HYUN KIM $^{1}$, JUNG-YEON KIM ${ }^{1}$, SUN-JAE LEE $^{1}$, \\ SANG-MI HAN ${ }^{2}$, KWANG-GILL LEE ${ }^{2}$, CHONG-KEE LEE ${ }^{3}$ and KWAN-KYU PARK ${ }^{1}$ \\ ${ }^{1}$ Department of Pathology, College of Medicine, Catholic University of Daegu, Daegu; ${ }^{2}$ Department of Agricultural Biology, \\ National Institute of Agricultural Science and Technology, Wanju; ${ }^{3}$ Department of Immunology, \\ College of Medicine, Catholic University of Daegu, Daegu, Republic of Korea
}

Received March 11, 2014; Accepted September 1, 2014

DOI: $10.3892 /$ ijmm.2014.1933

\begin{abstract}
Propionibacterium acnes (P. acnes) is a major contributing factor to the inflammatory component of acne. The many prescription medications for acne allow for a large number of potential combination treatments. However, several antibiotics, apart from their antibacterial effects, exert side-effects, such as the suppression of host inflammatory responses. Purified bee venom (BV) is a natural toxin produced by honeybees (Apis mellifera L.). BV has been widely used as a traditional medicine for various diseases. In the present study, to investigate the therapeutic effects of $\mathrm{BV}$ against $P$. acnesinduced inflammatory skin disease, $P$. acnes was intradermally injected into the ears of mice. After the injection, BV was applied to the skin surface of the right ear. Histological observation revealed that $P$. acnes induced a considerable increase in the number of infiltrated inflammatory cells. However, treatment with BV markedly reduced these reactions compared with the $P$. acnes-injected mice not treated with BV. Moreover, the expression levels of tumor necrosis factor (TNF)- $\alpha$, and interleukin (IL)- $1 \beta$ were significantly reduced in the BV-treated mice compared with the untreated $P$. acnes-injected mice. In addition, treatment with BV significantly inhibited Toll-like receptor (TLR)2 and CD14 expression in P. acnes-injected tissue. The binding activity of nuclear factor $-\kappa \mathrm{B}(\mathrm{NF}-\kappa \mathrm{B})$ and activator protein (AP)-1 was markedly suppressed following treatment with BV. The results from our study, using an animal model, indicate that BV exerts an inhibitory effect on inflammatory skin diseases. In conclusion, our data indicate that BV
\end{abstract}

Correspondence to: Professor Kwan-Kyu Park, Department of Pathology, College of Medicine, Catholic University of Daegu, 3056-6 Daemyung-4-Dong, Nam-gu, Daegu 705-718, Republic of Korea E-mail:kkpark@cu.ac.kr

*Contributed equally

Key words: bee venom, Propionibacterium acnes, anti-inflammatory, cytokines, Toll-like receptor has potential for use as an anti-acne agent and may be useful in the pharmaceutical and cosmetics industries.

\section{Introduction}

Acne is one of the most common skin disorders that affects millions of individuals (1). Propionibacterium acnes (P.acnes) is a major contributing factor to the inflammatory component of acne (2). The Gram-positive, anaerobic, lipophilic bacterium, $P$. acnes, is an ubiquitous member of the skin microbiota and is found in sebaceous follicles located on the face, chest and the back of the majority of humans (3). Acne presents with a number of different symptoms, including comedones, papules, pustules, nodules, cysts and pilosebaceous inflammation (4). The pathogenesis of acne is characterized by i) the excess sebum production and hyperplasia of sebaceous glands; ii) the formation of microcomedones, which is closely associated with the hyperkeratinization of the follicular wall and infundibulum; and iii) the induction of inflammatory reactions, such as the acceleration of cytokine production and arachidonic acid metabolism in keratinocytes, sebocytes and invaded inflammatory cells (5).

$P$.acnes contributes to the inflammatory reaction of acne by inducing monocytes and keratinocytes to produce pro-inflammatory cytokines, including tumor necrosis factor (TNF)- $\alpha$, and interleukin (IL)-1 $\beta$ and IL-8 (6). The inductino of these cykonines by $P$. acnes is mediated by Toll-like receptor (TLR)2 (7). TLRs are transmembrane proteins that play a critical role in the innate immune response to a variety of microbial pathogens (8). Pattern recognition receptors of the TLR protein family have been identified as $P$. acnes responsive receptors, and the expression of TLR 2 is elevated in P. acnes-infected keratinocytes, monocytes and macrophages (9). TLR activation promotes the production of pro-inflammatory cytokines, chemokines, prostaglandins and leukotrienes (10).

Although the early colonization with $P$. acnes plays an important role in the disease, the exact cause of acne and how treatment affects the course of the skin disease remain unclear (11). The many prescription medications for acne allow for a large number of potential combination treatments (11). Therapy targets the 4 factors responsible for lesion formation, i.e., increased sebum production, hyperkeratinization, coloni- 
zation by $P$. acnes and the resultant inflammatory reaction (12). Topical antibiotics and medications with bacteriostatic and anti-inflammatory properties are effective for treating mild to moderate inflammatory acne (13). However, several antibiotics, apart from their antibacterial effects, exert side-effects such as the suppression of host inflammatory responses (14-16). Thus, more systematic and safer agents are required.

Purified bee venom (BV) is a natural toxin produced by honeybees (Apis mellifera L.). BV has been widely used as a traditional medicine for various diseases $(17,18)$. Several studies have examined the biological and pharmacological activities of BV, including its anti-inflammatory effects anti-rheumatoid arthritis (17), pain-relief effects (19), anti-cancer cell proliferation (20) and immunomodulatory activity (21). However, to the best of our knowledge, the anti-inflammatory effects of BV on $P$. acnes-induced inflammatory skin disease in an animal model have not been reported to date. In the present study, we therefore demonstrate the potential of BV for use as an alternative to antibacterial therapy for the treatment of acne.

\section{Materials and methods}

Collection of $B V$. Colonies of natural honeybees (Apis mellifera L). used in this study were maintained at the National Academy of Agricultural Science, Wanju, Korea. BV was collected in collecting device (Chung Jin Biotech Co., Ltd., Ansan, Korea) in a sterile manner under strict laboratory conditions. In brief, the BV collector was placed on the hive, and the bees were given enough electric shocks which caused them to sting a glass plate from which dried BV was later scraped off. The collected BV was diluted in cold water and then centrifuged at $10,000 \mathrm{x}$ g for $5 \mathrm{~min}$ at $4^{\circ} \mathrm{C}$ to discard residues from the supernatant. Purified BV was lyophilized by a freeze dryer and stored in a refrigerator for later use, as previoulsy described (32). BV used in the experiment was confirmed with size exclusion gel chromatography (AKTA Explorer; GE Healthcare Bio-Sciences, Piscataway, NJ, USA) by dissolving in $0.02 \mathrm{M}$ phosphate-buffer with $0.25 \mathrm{M} \mathrm{NaCl}$ adjusted to $\mathrm{pH} 7.2$ using a Superdex Peptide column (Amersham Biosciences, Piscataway, NJ, USA and GE Healthcare).

Preparation of bacteria. P. acnes (ATCC 6919; American Type Culture Collection, Rockville, MD, USA) were obtained from the Korean Culture Center of Microorganisms (Seoul, Korea) and were cultured at $37^{\circ} \mathrm{C}$ on Reinforced Clostridial Medium (BD Diagnostics, Sparks, MD, USA) under anaerobic conditions at $37^{\circ} \mathrm{C}$ until reaching $\mathrm{OD}_{600} 1.0$ (logarithmic growth phase). The log phase bacterial culture was centrifuged at $5,000 \mathrm{x} \mathrm{g}$ at $4^{\circ} \mathrm{C}$ for $15 \mathrm{~min}$. Subsequently, the culture supernatant was removed, filtered (through a $0.22 \mu \mathrm{m}$ pore size filter), and used immediately or stored at $-20^{\circ} \mathrm{C}$. The bacterial pellet was washed 3 times in $100 \mathrm{ml}$ of phosphate-buffered saline (PBS) and finally suspended in $10 \mathrm{ml}$ of PBS. The $P$. acnes suspension was incubated at $80^{\circ} \mathrm{C}$ for $30 \mathrm{~min}$ for heat-killing reaction. The heat-killed $P$. acnes suspension was stored at $4^{\circ} \mathrm{C}$ until use.

Experimental animal model. Eight-week-old ICR mice $(\mathrm{n}=30)$ were supplied from Samtako (Osan, Korea) and were individually housed in polycarbonate cages and maintained under constant temperature $\left(22 \pm 2^{\circ} \mathrm{C}\right)$ and humidity conditions $(55 \%)$. The mice were allowed free access to food and water, and were maintained in an environment with a 12:12-h light/dark cycle. All surgical and experimental procedures used in the current study were approved by the Institutional Review Board (IRB) committee at the Catholic University of Daegu Medical Center, Daegu, Korea and conformed to the US National Institutes of Health guidelines for the care and use of laboratory animals.

The mice were randomly divided into 6 different groups (5 mice/group) as follows: i) NC, normal control. ii) PA, living $P$. acnes $\left[1.0 \times 10^{7}\right.$ colony-forming units $(\mathrm{CFU}) / 20 \mu 1$ in PBS] was intradermally injected into the left ears of the mice. The right ears received an equal amount $(20 \mu \mathrm{l})$ of PBS. iii) PA/ Vas, living $P$. acnes was intradermally injected into both the left and the right ears. After the injection, $0.05 \mathrm{~g}$ vaseline (Sigma, St. Louis, MO, USA) was applied to the surface of the skin of the right ear. For the next 3 groups, PA/BV1, PA/BV10 and PA/BV100, living $P$. acnes was intradermally injected into both the left and the right ears. After the injection, BV (1, 10 and $100 \mu \mathrm{g}$ mixed with $0.05 \mathrm{~g}$ vaseline) was applied to the surface of the skin of the right ear in the mice in each group. At the end of each treatment period ( $24 \mathrm{~h}$ later), the animals were sacrificed by cervical dislocation and the ears were excised.

Histological analysis. All tissue specimens were fixed in $10 \%$ formalin for at least $24 \mathrm{~h}$ at room temperature. Following fixation, perpendicular sections to the anterior-posterior axis of the wound were dehydrated in graded ethanol, cleared in xylene and embedded in paraffin. Thin sections ( $4-\mu \mathrm{m}$-thick) were mounted on glass slides, dewaxed, rehydrated in distilled water and stained with hematoxylin and eosin (H\&E). As part of the histological evaluation, a pathologist blinded to the previous treatment examined all the sections under a light microscope (Nikon, Tokyo, Japan).

Immunohistochemical staining. Paraffin-embedded tissue sections were deparaffinized with xylene, dehydrated in gradually decreasing concentrations of ethanol, and subsequently treated with $3 \%$ hydrogen peroxidase in methanol for $10 \mathrm{~min}$ to block endogenous peroxidase activity. Tissue sections were immersed in $10 \mathrm{mM}$ sodium citrate buffer ( $\mathrm{pH}$ 6.0) for $5 \mathrm{~min}$ at $95^{\circ} \mathrm{C}$. The final step was repeated using fresh $10 \mathrm{mM}$ sodium citrate solution ( $\mathrm{pH}$ 6.0). The sections were allowed to remain in the same solution while cooling for $20 \mathrm{~min}$ and rinsed in PBS. The sections were incubated with primary antibody (1:100) for $1 \mathrm{~h}$ at $37^{\circ} \mathrm{C}$. Primary antibodies were the following: anti-TNF- $\alpha$ (Abcam, Cambridge, UK) and anti-IL-1 $\beta$ (Santa Cruz Biotechnology, Inc., Santa Cruz, CA, USA). The signal was visualized using an EnVision System (Dako, Carpinteria, CA, USA) for $30 \mathrm{~min}$ at $37^{\circ} \mathrm{C}$. 3,3'-Diaminobenzidine tetrahydrochloride (DAB) was used as the coloring reagent, while hematoxylin was used as the counterstain.

Immunofluorescence staining. Paraffin-embedded ear tissue sections were deparaffinized with xylene and dehydrated in gradually decreasing concentrations of ethanol. The tissue sections were subsequently placed in blocking serum (5\% bovine serum albumin in PBS) at room temperature for $1 \mathrm{~h}$. Primary antibody (1:100 dilution) was added followed by 
overnight incubation at $4^{\circ} \mathrm{C}$, and incubation with secondary antibody (1:200 dilution) was performed at room temperature for $4 \mathrm{~h}$. Antibodies used in the experiments were the following: CD14, TLR2 (Santa Cruz Biotechnology, Inc.) and anti-mouse, anti-rabbit-biotinylated secondary antibodies conjugated with FITC or Texas Red (Invitrogen, Carlsbad, CA, USA). The slides were mounted using VECTASHIELD ${ }^{\circledR}$ Mounting Medium (VECTOR Laboratories, Inc., Burlingame, CA, USA). Specimens were examined and photographed using a fluorescence microscope (Nikon).

Western blot analysis. The tissues were lysed and homogenized in lysis buffer (50 mM Tris pH 8.0, $150 \mathrm{mM} \mathrm{NaCl}, 5 \mathrm{mM}$ EDTA, 0.5\% NP-40, $100 \mathrm{mM}$ PMSF, $1 \mathrm{M}$ DTT, $10 \mathrm{mg} / \mathrm{ml}$ leupeptin and aprotinin; all from Sigma). Following incubation on ice for $30 \mathrm{~min}$, the samples were centrifuged at $8,000 \mathrm{x} \mathrm{g}$ at $4^{\circ} \mathrm{C}$ for $30 \mathrm{~min}$, and the supernatant was collected. The total protein concentration was determined by Bradford assay (Bio-Rad Laboratories, Richmond, CA, USA). Total protein (10-50 $\mu \mathrm{g}$ ) was separated on 8-12\% SDS-polyacrylamide gels and transferred onto PVDF membranes (Millipore Corp., Billerica, MA, USA) using a standard SDS-PAGE gel electrophoresis procedure. The membranes were blocked in $5 \%$ skim milk in TBS-T (10 mM Tris, $150 \mathrm{mM} \mathrm{NaCl}$ and $0.1 \%$ Tween-20) for $2 \mathrm{~h}$ at room temperature and probed with primary antibody for $4 \mathrm{~h}$. A horseradish peroxidase (HRPO)conjugated secondary antibody (anti-mouse, anti-rabbit and anti-goat) was used for detection. Signals were detected using an enhanced chemiluminescence detection system (Amersham Biosciences, Piscataway, NJ, USA). The primary antibodies used in this study were the following: anti-TNF- $\alpha$ from Abcam, and anti-IL-1 $\beta$ and anti-glyceraldehyde 3-phosphatedehydrogenase (GAPDH) from Santa Cruz Biotechnology. All primary antibodies were diluted at 1:1,000. Signal intensity was quantified using an image analyzer (LAS-3000; Fujifilm, Tokyo, Japan).

Reverse-transcription polymerase chain reaction (RT-PCR). Total RNA was extracted from ear tissue with TRIzol reagent (Gibco, Grand Island, NY, USA) according to the manufacturer's recommendations. The purity and quantity of the RNA preparation were measured at optical densities of 260 and $280 \mathrm{~nm}$. First-strand cDNA was synthesized using oligo(dT) primers and M-MLV reverse-transcriptase (Promega Corp., Madison, WI, USA). An aliquot of cDNA was used for PCR using primer sets specific to mouse TNF- $\alpha$, IL-1 $\beta$ and GAPDH. Primer sequences were as follows: TNF- $\alpha$ forward, 5'-AGT GGT GCC AGC CGA TGG GTT GT-3' and reverse, 5'-GCT GAG TTG GTC CCC CTT CTC CAG-3'; IL-1 $\beta$ forward, 5'-CAT GAG CAC CTT CTT TTC CT-3' and reverse, 5'-TGT ACC AGT TGG GGA ACT CT-3'; GAPDH forward, 5'-GTG GAC ATT GTT GCC ATC AAC G-3' and reverse, 5'-GAG GGA GTT GTC ATA TTT CTC G-3'. PCR products were visualized by $1.5 \%$ agarose gel electrophoresis with ethidium bromide staining.

Nuclear protein extraction. Tissues were trypsinized and incubated for $15 \mathrm{~min}$ in a hypo-osmotic buffer $(10 \mathrm{mM}$ HEPES, pH 7.9, $10 \mathrm{mM}$ KCI, $1.5 \mathrm{mM} \mathrm{MgCl}_{2}, 0.2 \mathrm{mM}$ EDTA, $25 \%$ glycerol, $0.5 \mathrm{mM}$ DTT) for $20 \mathrm{~min}$, and vortexed and centrifuged at $5,000 \times \mathrm{g}$ for $15 \mathrm{~min}$ at $4^{\circ} \mathrm{C}$. The nuclear supernatant was collected as the nuclear lysate fraction. Each buffer also contained $0.2 \mathrm{mM}$ phenylmethanesulfonyl fluoride (PMSF) and $10 \mu \mathrm{g} / \mathrm{ml}$ protease inhibitors.

Electrophoretic mobility shift assay (EMSA). A DIG Gel Shift kit (Roche, Mannheim, Germany) was used for EMSA. The nuclear factor- $\kappa \mathrm{B}(\mathrm{NF}-\kappa \mathrm{B})$ and activator protein (AP)-1 oligonucleotide probe (NF- $\mathrm{B}, 5^{\prime}$-AGT TGA GGG GAC TTT CCC AGG C-3', AP-1, 5'-CGC TTG ATG ATG CAG CCG GAA-3'; only sense strands are shown) was end-labeled with DIG-ddPUT. For binding reactions, $9 \mu \mathrm{g}$ nuclear extract protein was mixed with binding buffer $(0.5 \mu \mathrm{g}$ poly $\mathrm{dI}-\mathrm{dC}, 0.1 \mu \mathrm{g}$ poly L-lysine and $0.8 \mu \mathrm{g}$ labeled oligonucleotide, final volume of $20 \mu \mathrm{l}$ ) and was incubated at $37^{\circ} \mathrm{C}$ for $30 \mathrm{~min}$. The nuclear protein-DNA complex was separated on a $6 \%$ non-denaturing polyacrylamide gel in TBE buffer at $80 \mathrm{~V}$ for $1.5-2 \mathrm{~h}$ at $4^{\circ} \mathrm{C}$. The samples were transferred to Hybond-XL membranes (Amersham Biosciences) by electroblotting for $30 \mathrm{~min}$. The membranes were cross-linked for $10 \mathrm{~min}$ and washed with solution containing $100 \mathrm{mM}$ maleic acid, $150 \mathrm{mM} \mathrm{NaCl}$ and $0.3 \%$ Tween-20, $\mathrm{pH} 7.5$ for $10 \mathrm{~min}$, were then moved to blocking solution (DIG Gel Shift kit) for $40 \mathrm{~min}$. The membranes were incubated with anti-digoxigenin-AP Fab fragments $(1: 10,000)$ for $30 \mathrm{~min}$, and the nuclear protein-DNA bands were developed with detection solution including $100 \mathrm{mM}$ Tris- $\mathrm{HCl}, 100 \mathrm{mM} \mathrm{NaCl}, \mathrm{pH} 9.5$ and $100 \mu \mathrm{g} / \mathrm{ml}$ disodium 3-\{4-methoxyspiro [1,2-dioxetane$3,2^{\prime}\left(5^{\prime}\right.$-chloro)tricyclo(3.3.1.1 $\left.1^{3,7}\right)$ decan]-4-yl\} phenyl phosphate. $\mathrm{NF}-\kappa \mathrm{B}$ and AP-1 bands from the films were quantitated using an image analyzer (LAS-3000; Fujifilm).

Statistical analysis. Data are presented as the means \pm SE. The Student's t-test was used to assess the significance of differences between independent experiments. A value of $\mathrm{p}<0.05$ was considered to indicate a statistically significant difference.

\section{Results}

Effects of BV on P. acnes-induced inflammatory skin disease. To investigate the therapeutic effects of BV against $P$. acnesinduced inflammatory skin disease, $P$. acnes was intradermally injected into both the left and the right ears of ICR mice. After the injection, various concentrations of $\mathrm{BV}(1,10$ and $100 \mu \mathrm{g})$ mixed with $0.05 \mathrm{~g}$ of vaseline were applied to the surface of the skin of the right ear. As shown in Fig. 1A, significant ear swelling, redness and erythema were observed $24 \mathrm{~h}$ after the $P$. acnes injection. Histological observation revealed that the $P$. acnes injection induced a considerable increase in the number of infiltrated inflammatory cells. By contrast, the BV-treated ears showed noticeably reduced ear thickness, swelling, erythema and inflammatory reactions. In particular, treatment with $1 \mu \mathrm{g}$ of $\mathrm{BV}$ resulted in a 3 -fold reduction of ear thickness compared to the ears injected only with living P. acnes (Fig. 1B). Based on these results, $1 \mu \mathrm{g}$ of BV was used in the subsequent experiments.

$B V$ suppresses pro-inflammatory cytokine expression. It has previously been demonstrated that $P$. acnes stimulates the production of pro-inflammatory cytokines, such as TNF- $\alpha$ and IL-1 $\beta$ (6). Therefore, we investigated whether TNF- $\alpha$ and IL-1 $\beta$ 
A

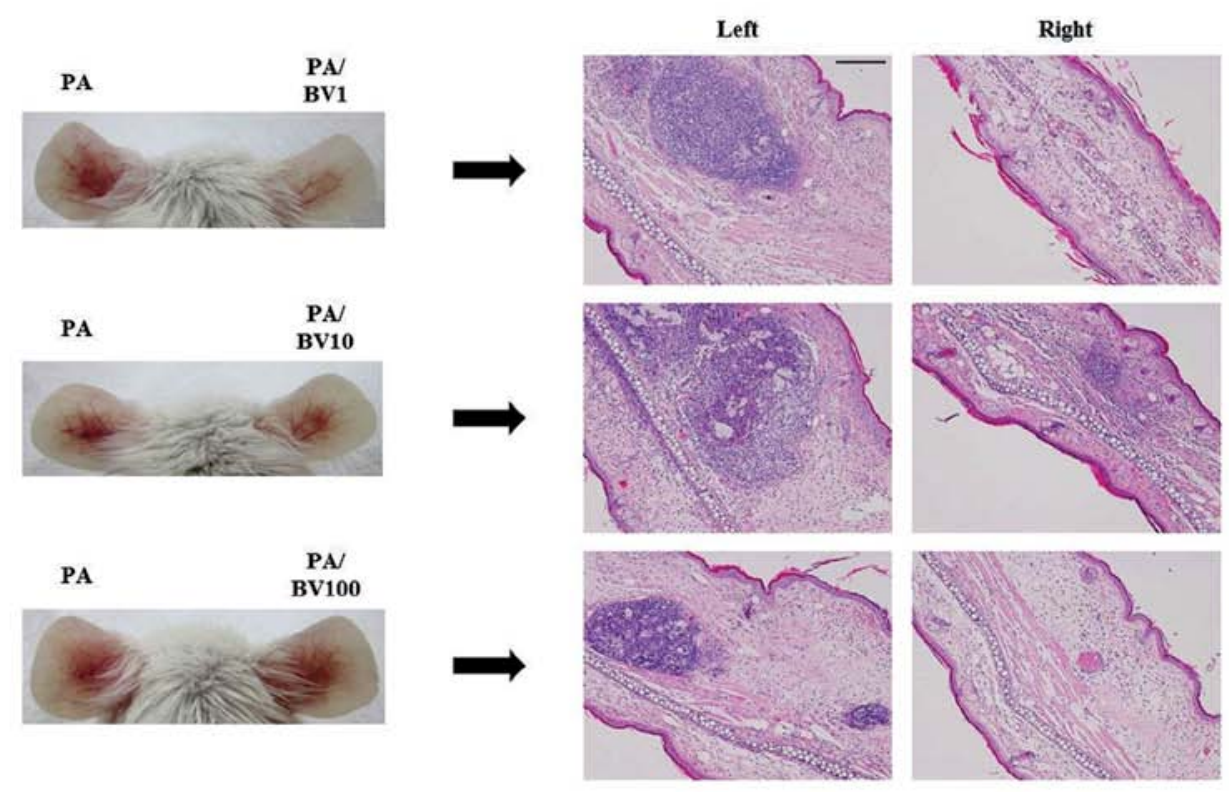

B
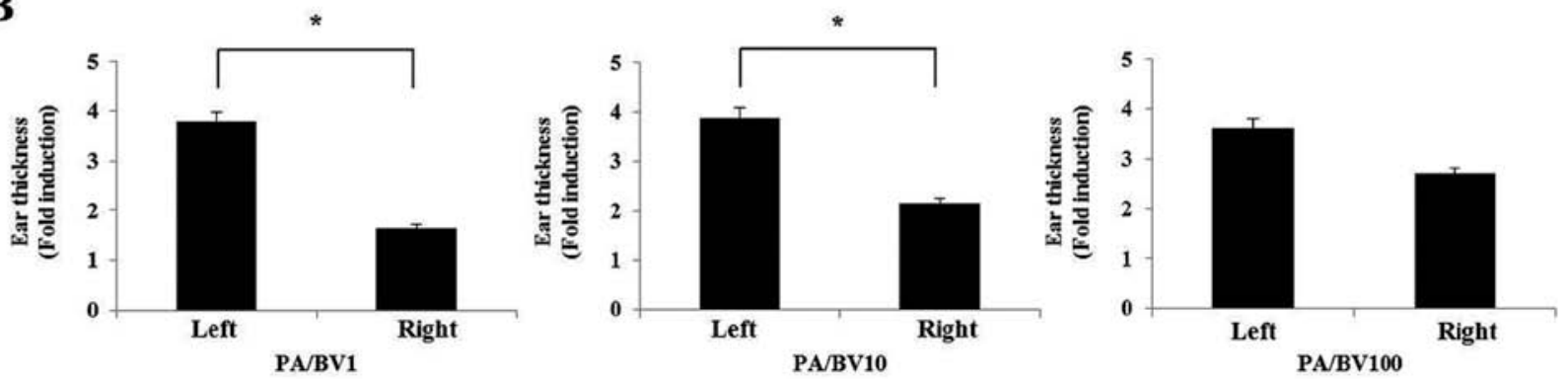

Figure 1. Bee venom (BV) inhibits inflammation in Propionibacterium acnes (P.acnes)-induced inflammatory skin disease. Ears of mice were injected intradermally with $1.0 \times 10^{7} \mathrm{CFU} / 20 \mu \mathrm{l}$ of P. acnes (left and right ears). BV (1,10 and $100 \mu \mathrm{g}$ in mixed with $0.05 \mathrm{~g}$ vaseline) was applied to the surface of the skin of the right ear of mice in each group after the injection of $P$. acnes. (A) An increase in ear thickness and in the number of infiltrating inflammatory cells surrounding the injection site of $P$. acnes was observed by hematoxylin and eosin (H\&E) staining; however, this increase was reversed in the presence of BV. (B) Numerical value of ear thickness. Representative images from each study group. PA, group injected with living P. acnes; PA/BV, group injected with living $P$. acnes and treated with BV mixed with vaseline $(1,10$ and $100 \mu \mathrm{g}$ of BV). Magnification, $\mathrm{x} 100$; scale bar, $100 \mu \mathrm{m}$. Results are expressed as the means $\pm \mathrm{SE}$ of 3 independent determinations. ${ }^{*} p<0.05$ compared to the right ear.

are involved in the inhibitory effects of $\mathrm{BV}$ on P.acnes-induced inflammatory skin disease. Immunohistochemical staining for TNF- $\alpha$ and IL- $1 \beta$ revealed that the expression levels of these cytokines were barely detectable in the normal skin tissue from the NC group. As shown in Fig. 2A, the PA and PA/Vas groups showed a marked increase in the number of TNF- $\alpha$ and IL-1 $\beta$-positive cells compared to the NC group. However, treatment with BV significantly inhibited the number of TNF- $\alpha$ - and IL-1 $\beta$-positive cells compared to the PA and PA/ Vas groups. Consistent with immunohistochemical staining, the results from western blot analysis revealed that treatment with BV suppressed the expression levels of these cytokines in the inflamed tissue (Fig. 2B). Moreover, the results from RT-PCR also indicated that treatment with BV markedly inhibited the expression of TNF- $\alpha$ and IL- $1 \beta$ in the PA/BV1 group (Fig. 2C). These observations suggested that BV effectively inhibited the inflammatory events in the animal model of $P$.acnes-induced inflammatory skin disease.

$B V$ inhibits TLR2 expression in inflamed skin tissue. To determine whether BV effectively blocks TLR2 and the macrophage marker of CD14, we performed double immunoflurorescence staining. As shown in Fig. 3, the PA and PA/Vas groups showed significantly higher TLR2 and CD14 expression levels than the NC group. In addition, merged images show that the PA group predominantly expressed CD14 in the dermis and TLR2 in the epidermis, both of which are localized at different parts of the tissue. These results demonstrated that P. acnes induced the infiltration of macrophages and the activation of TLR2 in the inflamed skin tissue. By contrast, treatment with BV significantly inhibited TLR2 and CD14 expression in the $P$. acnes-injected tissue. Therefore, $\mathrm{BV}$ effectively blocks the expression of TLR2 and CD14 in P. acnes-induced inflammatory skin disease.

$B V$ inhibits the DNA-binding activity of transcription factors. Pro-inflammatory cytokines are regulated at the transcriptional levels by several transcriptional factors, including AP-1 and NF-kB (22). Therefore, we examined the DNA-binding activity of NF- $\mathrm{KB}$ and AP-1 in inflamed skin tissue treated with or without BV by EMSA. As shown in Fig. 4A and B, the expression of NF- $\kappa \mathrm{B}$ and AP-1 was increased in the PA and 
$\mathbf{A}$
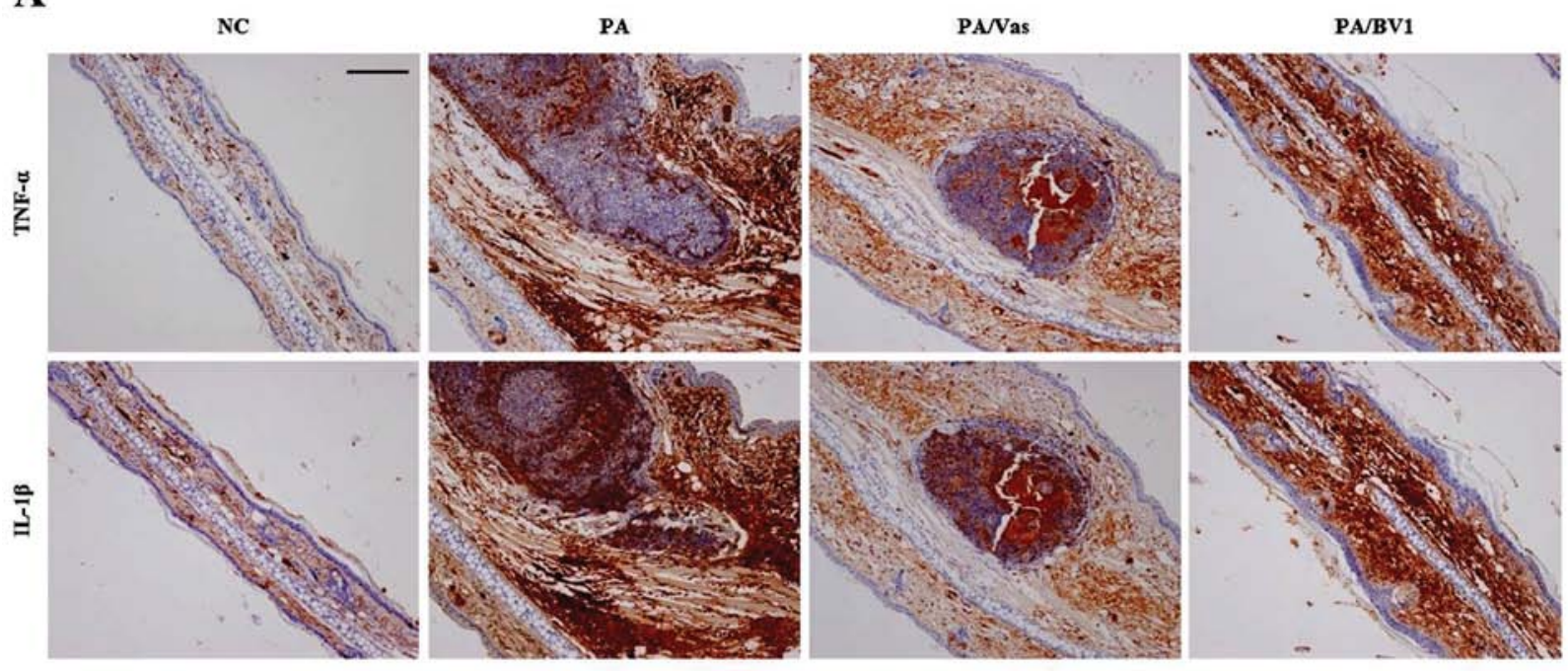

B

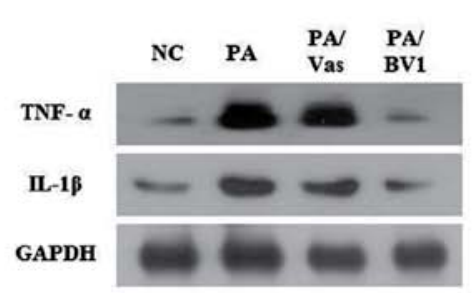

C

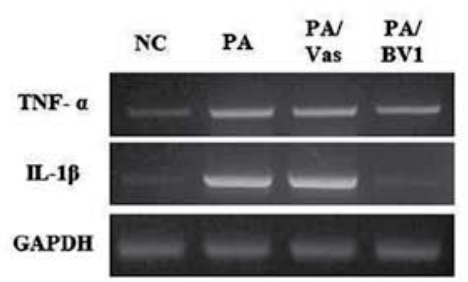

Figure 2. Bee venom (BV) inhibits the expression of pro-inflammatory cytokines in the inflamed skin tissue. (A) Expression levels of tumor necrosis factor (TNF)- $\alpha$ and interleukin (IL)-1 $\beta$ were barely detected in the NC group. Compared to the PA and PA/Vas groups, treatment with BV markedly suppressed the Propionibacterium acnes (P. acnes)-induced TNF- $\alpha$ and IL-1 $\beta$ expression. (B) Western blot analysis and (C) RT-PCR showed that the protein and mRNA expression levels of TNF- $\alpha$ and IL-1 $\beta$ were significantly increased in the PA/Vas group. However, these levels were decreased in the BV treatment group. NC, normal control; PA, group injected with living P. acnes; PA/Vas, group injected with living P. acnes and treated with vaseline; PA/BV1, group injected with living $P$. acnes and treated with $1 \mu \mathrm{g}$ of BV mixed with vaseline. GAPDH was used to confirm equal sample loading. Results are expressed as the means \pm SE of 3 independent determinations.
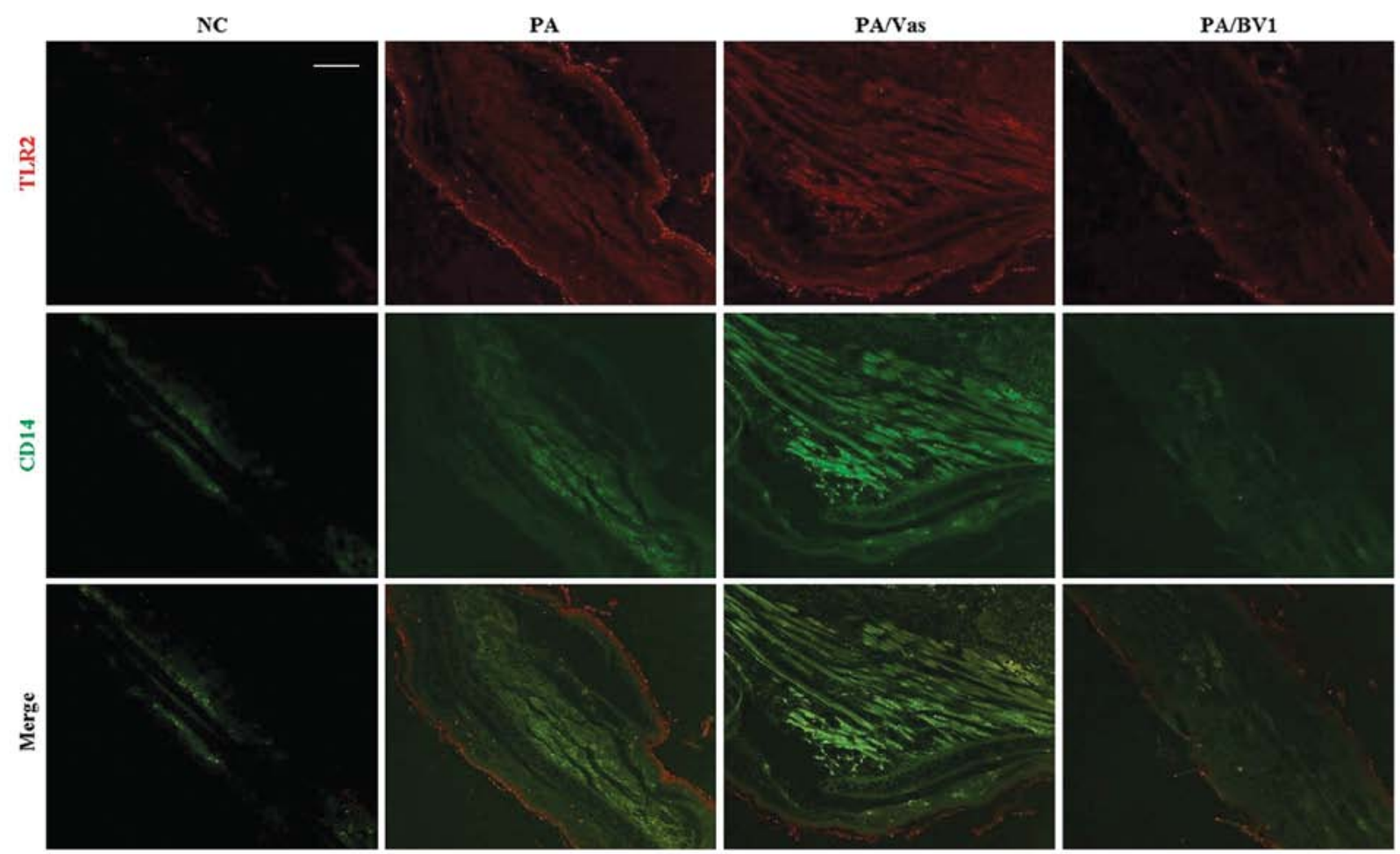

Figure 3. Bee venom (BV) inhibits Toll-like receptor (TLR) 2 and CD14 expression in inflamed skin tissue. Representative immnofluorescence images show that treatment with BV suppresseed TLR2 (Texas Red, red color) and CD14 (FITC, green color) expression in Propionibacterium acnes (P. acnes)-induced inflammatory skin disease. NC, normal control; PA, group injected with living P. acnes; PA/Vas, group injected with living P. acnes and treated with vaseline; $\mathrm{PA} / \mathrm{BV} 1$, group injected with living $P$. acnes and treated with $1 \mu \mathrm{g}$ of BV mixed with vaseline. Magnification, x100; scale bar, $100 \mu \mathrm{m}$. 

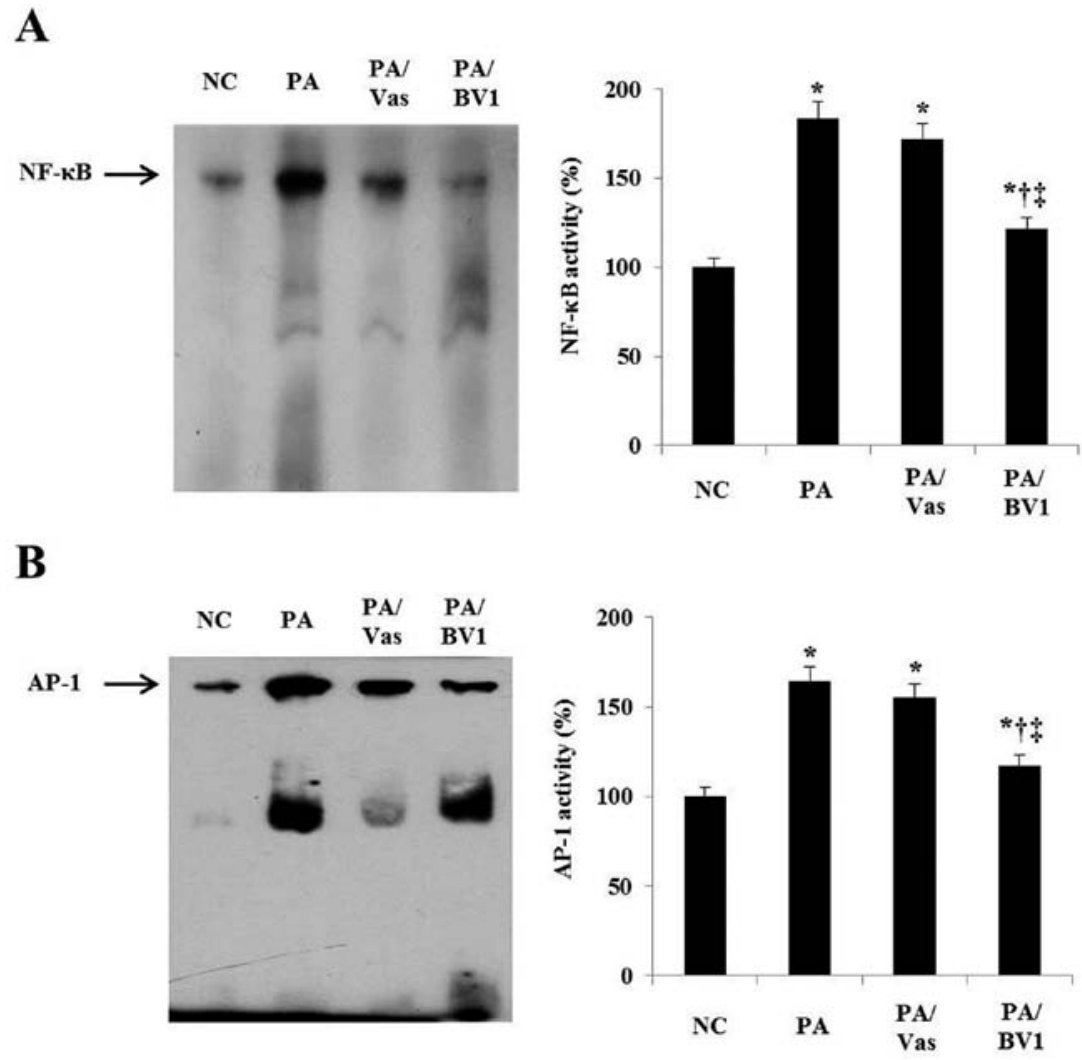

Figure 4. Bee venom (BV) inhibits the DNA-binding activity of transcription factors in inflammatory skin disease. Electrophoretic mobility shift assay (EMSA) showing treatment with BV inhibited the DNA-binding activity of (A) nuclear factor- $\mathrm{\kappa B}$ (NF- $\mathrm{\kappa B}$ ) and (B) activator protein (AP)-1 in Propionibacterium acnes (P. acnes)-induced inflammatory skin disease. NC, normal control; PA, group injected with living P. acnes; PA/Vas, group injected with living P. acnes and treated with vaseline; PA/BV1, group injected with living $P$. acnes and treated with $1 \mu \mathrm{g}$ of BV mixed vaseline. Results are expressed as the means $\pm \mathrm{SE}$ of 3 independent determinations. " $\mathrm{p}<0.05$ compared to the $\mathrm{NC}$ group. ${ }^{~} \mathrm{p}<0.05$ compared to the PA group. ${ }^{\hbar} \mathrm{p}<0.05$ compared to the PA/Vas group.

PA/Vas groups, but those levels were significantly inhibited in the PA/BV1 group. These results indicate that BV inhibits the expression of inflammatory cytokines, such as TNF- $\alpha$ and IL-1 $\beta$ by suppressing the DNA-binding activity of NF- $k B$ and AP-1 in the inflamed skin tissue. Therefore, these results suggest that $\mathrm{BV}$ is effective in inhibiting NF- $\mathrm{KB}$ and AP-1 activation in inflamed skin tissue, which provides the molecular basis for the decreased expression of chemokines/cytokines in the inflamed skin treated with BV following P.acnes injection.

\section{Discussion}

The majority of serious skin inflammatory diseases are due to infection by various microorganisms, including the Gram-positive P. acnes and Staphylococcus and the Gram-negative, Pseudomonas aeruginosa $(23,24)$. Colonization of the pilosebaceous follicle by $P$. acnes is a major factor for the inflammatory reaction in acne vulgaris. Therefore, $P$. acnes has been a major target of therapy in inflammatory acne (25). A number of skin disorders with an inflammatory component are treated with steroids and/or antibiotics in both oral and topical formulations (26). Topical therapies, including retinoids, benzoyl peroxide, azelaic acid and antibiotics, when used in combination, usually improve the condition of mild to moderate acne $(11,23)$. However, the long-term use of these drugs has potential side-effects, such as hypertension, immu- nosuppression (steroids) and the development of antibiotic resistance (27-29). Thus, safer and natural agents are required.

$\mathrm{BV}$, a natural toxinm contains a variety of peptides, including melittin, apamin, adolapin and mast cell degranulating peptide along with enzymes, biological amines and non-peptide components (18). A high concentration of BV $(100 \mu \mathrm{g} / \mathrm{ml})$ may lead to the instability of human lymphocytes. By contrast, low concentrations of BV are not genotoxic and do not produce oxidative damage (30). As a traditional alternative medical approach, BV therapy has been used to reduce pain and in the treatment of inflammatory diseases, such as rheumatoid arthritis and multiple sclerosis since ancient times (17). In a previous study, we investigated whether BV reduces atherosclerotic lesion formation via anti-inflammatory mechanisms (31). Previous studies have also demonstrated the antimicrobial activities of BV against $P$. acnes-induced inflammation in vitro (32). However, the anti-inflammatory effects of BV on P. acnes-induced inflammatory skin disease using an animal model have not yet been fully elucidated.

In the present study, we investigated whether BV regulates the expression of pro-inflammatory-related genes in a mouse model of skin tissue inflammation. A previous study suggested that $P$. acnes induces inflammation through the activation of TLR, particularly TLR 2 and TLR4 (10). The activation of TLR 2 and TLR4 has been shown to stimulate the release of pro-inflammatory cytokines, such as IL-1 $\alpha$, 
IL-1 $\beta$, IL-6, IL-8 and TNF- $\alpha$ (33). More specifically, TLR2 mediates host responses to peptidoglycan from Gram-positive bacteria, whereas TLR4 mediates host responses to lipopolysaccharide (LPS) from Gram-negative bacteria (34). The inflammation triggered through TLR2 is important in the pathogenesis of acne (25). Therefore, the regulation of TLR2 expression may provide a feasible target for the treatment of inflammatory acne lesions (2). To examine this hypothesis, we determined the effects of $\mathrm{BV}$ on the expression of the proinflammatory cytokines, TNF- $\alpha$ and IL-1 $\beta$, as well as TLR2 and CD14 in inflamed skin tissue. Our data indicate that BV is able to reduce various inflammatory events observed in the skin layers. Of note, BV regulated the production of TNF- $\alpha$ and IL-1 $\beta$ at the protein level and downregulated the mRNA expression of TNF- $\alpha$ and IL-1 $\beta$. Consistent with these findings, TLR2 and CD14 expression was also similarly suppressed by treatment with BV.

Monocytes, macrophages, sebocytes and keratinocytes are stimulated by $P$. acnes through a TLR2-mediated $\mathrm{NF}-\kappa \mathrm{B}$ signaling pathway during inflammatory reactions in skin $(10,35,36)$. The activation of TLR can also lead to the activation of other transcription factors, such as AP-1 (37). The transcription factors, $\mathrm{NF}-\kappa \mathrm{B}$ and $\mathrm{AP}-1$, have been reported to be activated in acne lesions (38). In this study, to explore the potential mechanisms underlying the inhibitory effects of BV on cytokine production, we investigated the nuclear activation of NF- $\kappa \mathrm{B}$ and AP-1 in P. acnes-induced skin inflammation. The injection of $P$. acnes potentially increased the expression of nuclear NF- $\kappa$ B and AP-1 in the skin tissue. However, treatment with $\mathrm{BV}$ markedly reduced the nuclear expression of NF- $\kappa \mathrm{B}$ and AP-1 in the inflamed skin. Our results indicate that BV exerts an inhibitory effect against inflammatory skin diseases.

In conlcusion, we demonstrate that BV blocks several skin inflammatory responses, such as the production of TNF- $\alpha$ and IL-1 $\beta$. The most important findings of this study are that BV inhibits the $P$. acnes-stimulated production and expression of pro-inflammatory cytokines through the modulation of TLR2mediated NF- $\kappa$ B and AP-1 signaling in inflamed skin tissue. Taken together, our results indicate that BV exerts an inhibitory effect on inflammatory skin diseases. Moreover, this in vivo acne-like model may be useful for the pharmacological evaluation of anti-acne agents. In conclusion, this study suggests that BV has potential for use as an anti-acne agent and may be useful in the pharmaceutical and cosmetics industries. Further studies are required in order to fully elucidate the efficacy and mechanisms of action of individual constituents of BV for the treatment of $P$. acnes-induced inflammation.

\section{Acknowledgements}

This study was supported by a grant from the Next-Generation BioGreen 21 Program (no. PJ009519), Rural Development Administration, Korea.

\section{References}

1. Tsai HH, Lee WR, Wang PH, Cheng KT, Chen YC and Shen SC: Propionibacterium acnes-induced iNOS and COX-2 protein expression via ROS-dependent NF- $\kappa \mathrm{B}$ and AP-1 activation in macrophages. J Dermatol Sci 69: 122-131, 2013.
2. Jung MK, Ha S, Son JA, et al: Polyphenon-60 displays a therapeutic effect on acne by suppression of TLR2 and IL-8 expression via down-regulating the ERK1/2 pathway. Arch Dermatol Res 304: 655-663, 2012.

3. Mak TN, Fischer N, Laube B, et al: Propionibacterium acnes host cell tropism contributes to vimentin-mediated invasion and induction of inflammation. Cell Microbiol 14: 1720-1733, 2012.

4. Nakatsuji T, Kao MC, Fang JY, et al: Antimicrobial property of lauric acid against Propionibacterium acnes: its therapeutic potential for inflammatory acne vulgaris. J Invest Dermatol 129: 2480-2488, 2009.

5. Pawin H, Beylot C, Chivot M, et al: Physiopathology of acne vulgaris: recent data, new understanding of the treatments. Eur J Dermatol 14: 4-12, 2004.

6. Vowels BR, Yang S and Leyden JJ: Induction of proinflammatory cytokines by a soluble factor of Propionibacterium acnes: implications for chronic inflammatory acne. Infect Immun 63: 3158-3165, 1995.

7. Kim J: Review of the innate immune response in acne vulgaris: activation of Toll-like receptor 2 in acne triggers inflammatory cytokine responses. Dermatology 211: 193-198, 2005.

8. Medzhitov R, Preston-Hurlburt P and Janeway CA Jr: A human homologue of the Drosophila Toll protein signals activation of adaptive immunity. Nature 388: 394-397, 1997.

9. Jugeau S, Tenaud I, Knol AC, et al: Induction of toll-like receptors by Propionibacterium acnes. Br J Dermatol 153: 1105-1113, 2005.

10. Kim J, Ochoa MT, Krutzik SR, et al: Activation of toll-like receptor 2 in acne triggers inflammatory cytokine responses. J Immunol 169: 1535-1541, 2002.

11. Williams HC, Dellavalle RP and Garner S: Acne vulgaris. Lancet 379: 361-372, 2012.

12. Titus S and Hodge J: Diagnosis and treatment of acne. Am Fam Physician 86: 734-740, 2012.

13. Feldman S, Careccia RE, Barham KL and Hancox J: Diagnosis and treatment of acne. Am Fam Physician 69: 2123-2130, 2004.

14. Labro MT: Immunomodulation by antibacterial agents. Is it clinically relevant? Drugs 45: 319-328, 1993.

15. Ayangco L and Sheridan PJ: Minocycline-induced staining of torus palatinus and alveolar bone. J Periodontol 74: 669-671, 2003.

16. Ramakrishna J, Johnson AR and Banner BF: Long-term minocycline use for acne in healthy adolescents can cause severe autoimmune hepatitis. J Clin Gastroenterol 43: 787-790, 2009.

17. Billingham ME, Morley J, Hanson JM, Shipolini RA and Vernon CA: Letter: An anti-inflammatory peptide from bee venom. Nature 245: 163-164, 1973.

18. Son DJ, Lee JW, Lee YH, Song HS, Lee CK and Hong JT: Therapeutic application of anti-arthritis, pain-releasing, and anti-cancer effects of bee venom and its constituent compounds. Pharmacol Ther 115: 246-270, 2007.

19. Kwon YB, Lee JD, Lee HJ, et al: Bee venom injection into an acupuncture point reduces arthritis associated edema and nociceptive responses. Pain 90: 271-280, 2001.

20. Pérez-Payá E, Houghten RA and Blondelle SE: The role of amphipathicity in the folding, self-association and biological activity of multiple subunit small proteins. J Biol Chem 270: 1048-1056, 1995.

21. Park HJ, Lee SH, Son DJ, et al: Antiarthritic effect of bee venom: inhibition of inflammation mediator generation by suppression of NF-kappaB through interaction with the p50 subunit. Arthritis Rheum 50: 3504-3515, 2004.

22. Khalaf H, Jass J and Olsson PE: Differential cytokine regulation by NF-kappaB and AP-1 in Jurkat T-cells. BMC Immunol 11: 26, 2010.

23. Dryden MS: Skin and soft tissue infection: microbiology and epidemiology. Int J Antimicrob Agents 34 (Suppl 1): S2-S7, 2009.

24. Sohail MR, Gray AL, Baddour LM, Tleyjeh IM and Virk A: Infective endocarditis due to Propionibacterium species. Clin Microbiol Infect 15: 387-394, 2009.

25. Dessinioti C and Katsambas AD: The role of Propionibacterium acnes in acne pathogenesis: facts and controversies. Clin Dermatol 28: 2-7, 2010.

26. Grange PA, Raingeaud J, Calvez V and Dupin N: Nicotinamide inhibits Propionibacterium acnes-induced IL-8 production in keratinocytes through the NF-kappaB and MAPK pathways. J Dermatol Sci 56: 106-112, 2009.

27. Fivenson DP, Breneman DL, Rosen GB, Hersh CS, Cardone S and Mutasim D: Nicotinamide and tetracycline therapy of bullous pemphigoid. Arch Dermatol 130: 753-758, 1994. 
28. Zemtsov A and Neldner KH: Successful treatment of dermatitis herpetiformis with tetracycline and nicotinamide in a patient unable to tolerate dapsone. J Am Acad Dermatol 28: 505-506, 1993.

29. Handfield-Jones S, Jones S and Peachey R: High dose nicotinamide in the treatment of necrobiosis lipoidica. Br J Dermatol 118 693-696, 1988

30. Lee WR, Park JH, Kim KH, Park YY, Han SM and Park KK: Protective effects of melittin on transforming growth factor-betal injury to hepatocytes via anti-apoptotic mechanism. Toxicol Appl Pharmacol 256: 209-215, 2011.

31. Lee WR, Kim SJ, Park JH, et al: Bee venom reduces atherosclerotic lesion formation via anti-inflammatory mechanism. Am J Chin Med 38: 1077-1092, 2010.

32. Han SM, Lee KG, Yeo JH, Baek HJ and Park KK: Antibacterial and anti-inflammatory effects of honeybee (Apis mellifera) venom against acne-inducing bacteria. J Med Plants Res 4: 459-464, 2010

33. Lyte P, Sur R, Nigam A and Southall MD: Heat-killed Propionibacterium acnes is capable of inducing inflammatory responses in skin. Exp Dermatol 18: 1070-1072, 2009.
34. Mandell L, Moran AP, Cocchiarella A, et al: Intact gram-negative Helicobacter pylori, Helicobacter felis, and Helicobacter hepaticus bacteria activate innate immunity via toll-like receptor 2 but not toll-like receptor 4. Infect Immun 72: 6446-6454, 2004.

35. Köllisch G, Kalali BN, Voelcker V, et al: Various members of the Toll-like receptor family contribute to the innate immune response of human epidermal keratinocytes. Immunology 114: 531-541, 2005.

36. Kurokawa I, Danby FW, Ju Q, et al: New developments in our understanding of acne pathogenesis and treatment. Exp Dermatol 18: 821-832, 2009.

37. Scharf S, Hippenstiel S, Flieger A, Suttorp N and N'Guessan PD: Induction of human $\beta$-defensin- 2 in pulmonary epithelial cells by Legionella pneumophila: involvement of TLR2 and TLR5, p38 MAPK, JNK, NF-kappaB, and AP-1. Am J Physiol Lung Cell Mol Physiol 298: L687-L695, 2010.

38. Kang S, Cho S, Chung JH, Hammerberg C, Fisher GJ and Voorhees JJ: Inflammation and extracellular matrix degradation mediated by activated transcription factors nuclear factor-kappaB and activator protein-1 in inflammatory acne lesions in vivo. Am J Pathol 166: 1691-1699, 2005. 